\title{
SIFAT FISIK PAVING BLOCK KOMPOSIT SEBAGAI LAPIS PERKERASAN BEBAS GENANGAN AIR (PERMEABLE PAVEMENT)
}

\author{
Elsyani Eka Putri ${ }^{1}$, Ismeddiyanto ${ }^{2}$, Reni Suryanita ${ }^{3}$ \\ Program Studi S1 Teknik Sipil, Fakultas Teknik, Universitas Riau \\ Kampus Bina Widya J. HR Soebrantas KM 12,5 Pekanbaru, Kode Pos 28293 \\ Email: elsyani.eka@student.unri.ac.id, ismed.diyanto@lecturer.unri.ac.id, reni.suryanita@eng.unri.ac.id
}

\begin{abstract}
ABSTRAK
Peningkatan pembangunan menyebabkan semakin berkurangnya daerah resapan air. Hal ini dapat mengganggu sistem hidrologi dan menyebabkan banjir ketika musim hujan. Alternatif untuk mengatasi masalah tersebut digunakan suatu inovasi paving block komposit yang merupakan perpaduan antara paving block dan beton porous. Penelitian ini bertujuan mempelajari pengaruh penambahan beton porous terhadap sifat fisik paving block komposit yaitu densitas, absorbsi dan laju infiltrasi. Paving block komposit dirancang memiliki kemampuan meloloskan air dan mutu yang baik. Paving block komposit diisi dengan beton porous dengan variasi diameter 1 11/2", 2", 2 1/2" dan 3". Paving block komposit berbentuk segi enam dengan sisi $100 \mathrm{~mm}$ dan tebal $80 \mathrm{~mm}$. Nilai FAS dari campuran paving block dan beton porous adalah 0,4 dan 0,3 sedangkan perbandingan semen dan agregat adalah $1: 3$. Hasil penelitian menunjukkan semakin bertambahnya persentase beton porous pada paving block semakin rendah nilai densitas dan absorbsi. Disisi lain, paving block komposit yang memiliki kuat tekan tertinggi memiliki laju infiltrasi terendah. Nilai optimum laju infiltrasi paving block komposit sebesar 2,78 mm/s dengan kuat tekan 20,8 MPa. Berdasarkan hasil pengujian dapat disimpulkan bahwa inovasi paving block komposit dapat dijadikan sebagai lapis perkerasan yang memiliki kemampuan meloloskan air (permeable pavement).
\end{abstract}

Kata Kunci: absorbsi, densitas, laju infiltrasi, paving block komposit

\begin{abstract}
The development in construction has led to the reduction of water catchment area. This situation could disrupt the hydrological system and caused floods during rainy season. An alternative to overcome this this issue is the use of paving block composite; which isthe combination of concrete paving block and porous concrete. This research aims to study effect of the addition of porous concrete to the physical properties of paving block composite, e.g : the density, the absorption and the infiltration rate. The specimen was designed to have the ability to escape the water and and maintain its quality in good condition. The specimen was filled with the porous concrete with the variation of diameter of 11/2”, 2", $2^{1 / 2}$ ", and 3". The specimen was a six-sides polygon, with the length of each size of $100 \mathrm{~mm}$ and the thick of $80 \mathrm{~mm}$. The water ratio of concrete paving block and the porous concrete were 0.4 and 0.3 , respectively while the composition of cement and aggregate for each was $1: 3$. The results showed that the higher the porous concrete used in paving block the lower the value of its density and its absorption. On the other hand, higher compressive strength resulted in lower infiltration rate of the composite paving block. The optimum infiltration rate of 2,78 $\mathrm{mm} / \mathrm{s}$ was achieved on the specimen with the compressive strengthof 20,8 MPa. Based on the results of testing, it can be concluded that the innovation of composite paving blocks has good quality and has the ability to escape water, making it possible to reduce waterlogging.
\end{abstract}

Keywords: absorption, density, infiltration rate, composite paving blocks

\section{PENDAHULUAN}

Beralihnya fungsi lahan menjadi kawasan pembangunan, menyebabkan meningkatnya luas daerah yang ditutupi oleh lapisan perkerasan. Hal ini dapat mempengaruhi sistem hidrologi dimana air tidak dapat meresap ke dalam tanah dan memungkinkan aliran permukaan (run off) menjadi lebih besar sehingga menimbulkan genangan atau banjir karena saluran air yang tidak mempunyai kapasitas yang cukup untuk mengalirkan kelebihan air.

Telah dilakukan upaya untuk mengatasi hal tersebut yaitu dengan membuat lapis perkerasan beton yang bersifat porous. Beton porous adalah jenis beton khusus yang memiliki porositas tinggi yang memungkinkan air hujan dan air dari sumbersumber lain untuk dapat melewatinya, sehingga mengurangi aliran permukaan dan meningkatkan muka air tanah [5]. Akan tetapi, beton porous memiliki mutu yang rendah sehingga 
penggunaannya kurang efektif sebagai lapis perkerasan. Untuk mempertahankan mutu beton porous tanpa mengurangi kemampuannya dalam meloloskan air, dibuat suatu inovasi penggabungan dua jenis lapis perkerasan yaitu beton porous dan paving block.

Inovasi ini disebut paving block komposit dimana beton porous diletakkan pada bagian tengah paving block, dapat dilihat pada Gambar 1. Paving block berperan sebagai pengekang beton porous sehingga apabila diberi tekanan pada permukaannya beton porous tetap dapat mempertahankan kekuatannya hingga paving block dan beton porous mengalami kegagalan secara bersamaan. Hal ini juga dilakukan dilakukan agar kemampuan meloloskan air dari beton porous tetap dapat dipertahankan sehingga dapat dijadikan sebagai solusi untuk mengurangi genangan air.

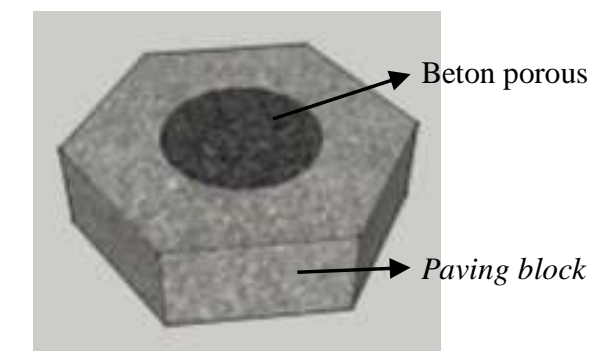

Gambar 1. Paving Block Komposit

\section{TINJAUAN PUSTAKA}

\section{Beton Porous}

Beton porous merupakan beton khusus yang memiliki sifat permeabilitas yang tinggi, bobotnya yang ringan dan tidak/sedikit menggunakan butiran halus.

Menurut ACI (American Concrete Institut) 522R-10 mengenai Pervious Concrete, beton berpori memiliki kuat tekan sebesar 400 sampai 4000 psi (2,8 $\mathrm{MPa}$ sampai dengan $28 \mathrm{MPa})$. Berat jenis beton porous umumnya berkisar $70 \%$ dari beton konvensional atau beton normal, jika dibuat dengan menggunakan bahan yang sama. Berat jenis beton porous bervariasi dari 1602 sampai $1922 \mathrm{~kg} / \mathrm{m}^{3}$.

Beton porous dapat diaplikasikan di area parkir, jalur jalan dengan lalu lintas ringan, trotoar pejalan kaki serta permukiman yang berwawasan lingkungan.

[6] :

Beton non-pasir mempunyai kelebihan yaitu

1. Bobot yang ringan

2. Tidak ada kecenderungan untuk bersegregasi

3. Kebutuhan semen sedikit

4. Cara pembuatan sederhana

5. Mudah meloloskan air

\section{Paving Block}

Paving block adalah suatu bata beton yang komposisi bahannya dibuat dari campuran semen portland atau bahan perekat hidrolis sejenisnya, air dan agregat dengan atau tanpa bahan tambahan lainnya yang tidak mengurangi mutu bata beton itu [7].

Paving block yang mempunyai kualitas baik merupakan paving block yang mempunyai nilai kuat tekan yang tinggi dan nilai absorbsi (persentasi penyerapan air) yang rendah. Syarat mutu paving block menurut SNI 03-0691-1996 dapat dilihat pada Tabel 1.

Tabel 1. Sifat - sifat fisik paving block

\begin{tabular}{|c|c|c|c|c|c|}
\hline \multirow[t]{2}{*}{ Mutu } & \multicolumn{2}{|c|}{$\begin{array}{c}\text { Kuat Tekan } \\
(\mathrm{MPa})\end{array}$} & \multicolumn{2}{|c|}{$\begin{array}{l}\text { Ketahanan } \\
\text { Aus } \\
(\mathrm{mm} / \text { menit })\end{array}$} & \multirow{2}{*}{$\begin{array}{c}\text { Penyerapan } \\
\text { Air Rata- } \\
\text { rata Maks. } \\
(\%)\end{array}$} \\
\hline & $\begin{array}{c}\text { Rata- } \\
\text { rata }\end{array}$ & Min & $\begin{array}{c}\text { Rata- } \\
\text { rata }\end{array}$ & Min & \\
\hline A & 40 & 35 & 0,09 & 0,103 & 3 \\
\hline B & 20 & 17 & 0,13 & 0,149 & 6 \\
\hline $\mathrm{C}$ & 15 & 12,5 & 0,16 & 0,184 & 8 \\
\hline D & 10 & 8,5 & 0,219 & 0,251 & 10 \\
\hline
\end{tabular}

\section{Bahan Tambah}

Bahan tambah merupakan suatu bahan yang dapat ditambahkan ke dalam adukan beton pada saat pengadukan, dengan tujuan agar dapat mengubah sifat adukan beton itu sendiri.

1. Silika fume

Berdasarkan ASTM C 618-86 mengenai Spesification for Silica Fume for Use in Hydaulic Cemen Concrete and Mortar, silika fume adalah suatu bahan berdiameter 1/100 diameter semen dan berbentuk bulat serta mengandung $\mathrm{SiO}_{2}$ lebih besar dari $85 \%$.

Apabila ditinjau dari sifat kimianya, silika fume dapat mengisi rongga-rongga di antara bahan semen, sehingga menyebabkan diameter pori yang mengecil serta total volume pori juga berkurang. Sedangkan dari sifat mekaniknya, silika fume apabila bereaksi terhadap batu kapur yang dilepas semen akan memiliki reaksi yang bersifat pozzolan.

2. Abu Batu

Abu batu merupakan suatu bahan yang berasal dari hasil proses penghancuran bongkahan batu yang difungsikan untuk kombinasi campuran beton.

Abu batu memiliki tekstur yang sangat tajam, sehingga apabila digunakan sebagai campuran beton dapat membuat ikatan di dalam beton menjadi sangat kuat, yang akhirnya dapat membuat kekuatan beton semakin meningkat.

3. Fiber

Fiber merupakan bahan yang ditambahkan pada beton berserat. Biasanya, fiber dijadikan sebagai bahan dasar yang digunakan dalam memproduksi bahan yang terbuat dari plastik. Fiber memiliki bentuk filamen-filamen atau 
potongan-potongan memanjang yang ketika dicampurkan kedalam adukan beton akan terurai.

Keuntungan dari penggunaan fiber dalam campuran beton adalah sebagai berikut :

a. Memperbaiki daya ikat matriks beton sehingga mengurangi penyusutan.

b. Meningkatkan kuat tekan dan kuat tarik lentur beton.

c. Mengurangi retak akibat penyusutan pada campuran beton.

d. Meningkatkan daktilitas.

\section{Sifat Fisik Paving Block Komposit}

1. Densitas

Densitas merupakan massa jenis suatu benda, dimana pengukuran massa setiap volume benda. Semakin tinggi nilai densitas rata-rata suatu benda, maka semakin besar pula nilai massa setiap volumenya. Pengujian densitas dilaksanakan berdasarkan ASTM C 1688 M -10.

$$
\rho=\frac{m}{v}
$$

Dengan :

$$
\begin{array}{ll}
\rho & =\operatorname{densitas}\left(\mathrm{gr} / \mathrm{cm}^{2}\right) \\
\mathrm{m} & =\operatorname{massa}(\mathrm{gr}) \\
\mathrm{v} & =\text { volume }\left(\mathrm{cm}^{3}\right)
\end{array}
$$

2. Absorbsi

Absorbsi merupakan persentase berat air yang mampu diserap oleh suatu material jika direndam dalam air. Pengujian penyerapan air (absorbsi) mengacu pada standar SNI 03-06911996.

$$
\text { absorbsi }=\frac{A-B}{B} \times 100 \%
$$

Dengan :

$\mathrm{A} \quad=$ berat paving block kondisi basah (gr)

$\mathrm{B}=$ berat paving block kondisi kering (gr)

3. Laju Infiltrasi

Infiltrasi adalah suatu peristiwa meresapnya air ke dalam tanah melalui permukaan tanah secara vertikal. Sedangkan laju infiltrasi merupakan banyaknya air yang masuk melalui permukaan tanah persatuan waktu.

Prosedur pengujian laju infiltrasi ini terdapat pada ASTM C1701. Dimana tujuan pengujian ini dilakukan untuk mengetahui kecepatan air mengalir dari permukaan ke dasar paving block komposit.

$$
I=\frac{4 V}{D^{2} \pi t}
$$

Dengan :

I = laju infiltrasi $(\mathrm{mm} / \mathrm{s})$

$\mathrm{V} \quad$ = volume air yang lolos $\left(\mathrm{mm}^{3}\right)$
$\mathrm{D}=$ diameter plastik $(\mathrm{mm})$

$\mathrm{t} \quad=$ waktu yang dibutuhkan meloloskan air (s)

\section{METODOLOGI PENELITIAN}

\section{Bahan Penelitian}

Bahan-bahan yang digunakan dalam penelitian ini diantaranya adalah sebagai berikut :

1. Semen PCC.

2. Agregat kasar berdiameter 5-10 mm untuk paving block dan 10-20 mm untuk beton porous.

3. Agregat halus dengan diameter lolos saringan No. 4 untuk paving block.

4. Bahan Tambah : silika fume, abu batu dan fiber

\section{Pengujian Karakteristik Material}

Pengujian karakteristik material adalah pengujian untuk agregat kasar dan agregat halus yang berguna untuk mengetahui sifat dan karakteristik material.

Penelitian ini menggunakan agregat kasar yang berupa batu pecah gunung dan campuran batu pecah koral yang berasal dari daerah Pangkalan, Sumatera Barat yang terdiri dari pengujian analisa saringan, kadar air, berat volume, berat jenis, dan pengujian abrasi menggunakan mesin Los Angeles. Sedangkan agregat halus berupa pasir yang diperoleh dari sungai didaerah Danau Bingkuang, Kampar yang terdiri dari pengujian analisa saringan, kadar air, berat volume, berat jenis, pemeriksaan kadar lumpur dan pemeriksaan kadar organik.

\section{Perencanaan Pembuatan Benda Uji}

Benda uji yang digunakan pada penelitian ini adalah paving block berbentuk segi enam dengan ukuran sisi $100 \mathrm{~mm}$ dan tebal $80 \mathrm{~mm}$ serta di tengahnya diisi beton porous dengan ukuran diameter $1 \frac{1}{2}{ }^{\prime}(38,10 \mathrm{~mm}), 2$ ' $(50,80 \mathrm{~mm}), 2 \mathrm{1} / 2$ ' $(63,50 \mathrm{~mm})$ dan 3' $(76,20 \mathrm{~mm})$. Sketsa dimensi benda uji dapat dilihat pada Gambar 2 .

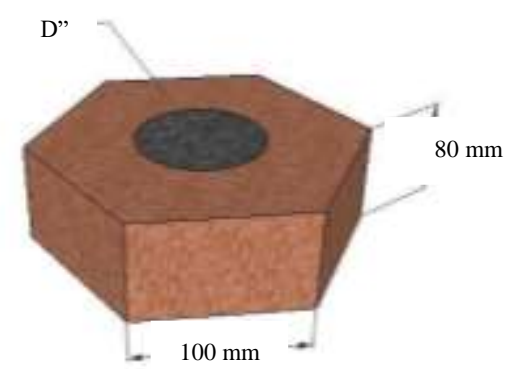

Gambar 2. Sketsa Dimensi Benda Uji

Untuk penelitian ini menggunakan 6 variasi sampel yaitu paving block normal, paving block komposit 1 1/2", paving block komposit 2", paving block komposit 2 1/2", paving block komposit 3" dan paving block keseluruhannya diisi beton porous. 
Rencana dan sketsa variasi benda uji dapat dilihat pada Tabel 2 dan Gambar 3.

Tabel 2. Rencana Benda Uji

\begin{tabular}{|c|c|c|c|c|c|c|}
\hline \multirow{3}{*}{ Pengujian } & \multicolumn{5}{|c|}{ Paving Block } & \multirow{3}{*}{$\begin{array}{l}\text { Beton } \\
\text { Porous }\end{array}$} \\
\hline & \multirow{2}{*}{$\begin{array}{c}\text { Paving } \\
\text { Block } \\
\text { Normal }\end{array}$} & \multicolumn{4}{|c|}{$\frac{\text { Komposit }}{\text { Diameter Pipa }}$} & \\
\hline & & $\begin{array}{c}1 \\
1 / 2\end{array}$ & $2^{\prime}$ & $\begin{array}{c}2 \\
1 / 2\end{array}$ & $3^{\prime}$ & \\
\hline Densitas & 5 & 5 & 5 & 5 & 5 & 5 \\
\hline Porositas & 5 & 5 & 5 & 5 & 5 & 5 \\
\hline $\begin{array}{c}\text { Laju } \\
\text { Infiltrasi }\end{array}$ & 5 & 5 & 5 & 5 & 5 & 5 \\
\hline
\end{tabular}

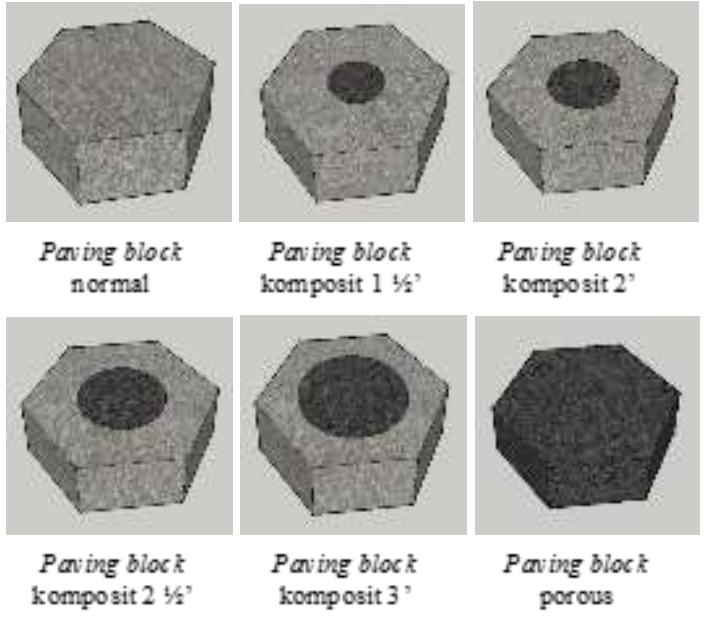

Gambar 3. Sketsa Benda Uji

\section{Perencanaan Campuran Benda Uji}

Hasil pengujian karakteristik agregat digunakan untuk memperoleh data-data dalam perencanaan komposisi campuran beton porous dan paving block (mix design). Komposisi untuk beton porous nilai FAS 0,4 dan perbandingan semen : agregat kasar adalah 1: 3 sedangkan untuk paving block nilai FAS 0,25 dan perbandingan semen : agregat halus adalah $1: 3$.

Untuk campuran paving block digunakan silika fume dengan kadar 3\% dari jumlah pasta. Pada campuran beton porous digunakan abu batu dengan kadar 1 - 2\% dari jumlah pasta, silika fume kadar 3\% dari jumlah pasta dan fiber dengan kadar $2,5 \%$ dari jumlah pasta. Rincian komposisi campuran paving block komposit yang digunakan untuk semua sampel dapat dilihat pada Tabel 3.

Tabel 3. Rincian Komposisi Campuran Paving Block Komposit 90 Sampel

\begin{tabular}{ccc}
\hline $\begin{array}{c}\text { Berat Bahan } \\
(\mathrm{kg})\end{array}$ & Beton Porous & Paving Block \\
\hline Semen & 68,43 & 21,20
\end{tabular}

$\begin{array}{ccc}\text { Agregat Kasar } & - & 75,47 \\ \text { Agregat Halus } & 264,90 & - \\ \text { Air } & 17,11 & 8,48 \\ \text { Silika Fume } & 2,05 & 0,64 \\ \text { Abu Batu } & - & 0,21 \\ \text { Fiber } & - & 0,53\end{array}$

\section{Pelaksanaan Pembuatan Benda Uji}

Pelaksanaan benda uji dilaksanakan di Laboratorium Teknologi Bahan Jurusan Teknik Sipil, Fakultas Teknik, Universitas Riau dan Bukit Barisan Batako Jalan Pesantren, Kulim, Tenayan Raya.

Prosedur pembuatan benda uji dilakukan dua tahap, yaitu pembuatan paving block dan beton porous.

1. Paving Block

Langkah-langkah dalam pengadukan

campuran paving block yaitu :

a. Menimbang material sesuai komposisi mix design yang telah direncanakan.

b. Memasukkan material kedalam mixer pengaduk.

c. Setelah adukan tercampur merata, keluarkan adukan dari mesin mixer.

d. Letakkan paralon dibagian tengah cetakan seperti pada Gambar 4, lalu masukkan adukan sedikit demi sedikit ke dalam mesin press paving block sambil digetarkan.

e. Setelah cetakan penuh, tarik tuas mesin press hingga beban dari mesin press jatuh dan memadatkan paving block di dalam cetakan.

f. Lalu tarik lagi tuas mesin press keatas untuk mengeluarkan paving block dari cetakan.

g. Mencabut paralon dari paving block yang sudah padat.

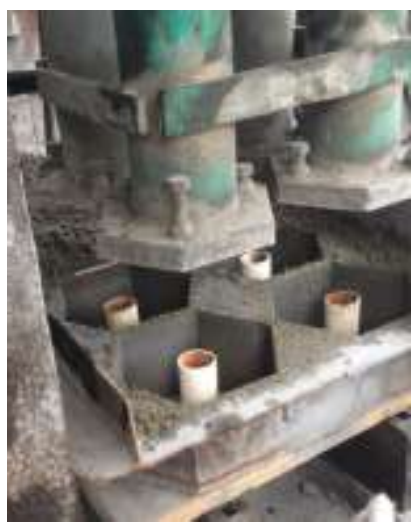

Gambar 4. Paralon pada Bagian Tengah Cetakan Paving Block

2. Beton Porous

Langkah-langkah dalam pengadukan campuran paving block yaitu :

a. Menimbang material sesuai komposisi mix design yang telah direncanakan.

b. Memberi semen basah dipermukaan lubang pada paving block. 
c. Setelah itu dilanjutkan dengan mengaduk material beton porous.

d. Setalah adukan tercampur merata, masukan adukan beton porous kedalam lubang paving block hingga penuh dan padat, dapat dilihat pada Gambar 5.

e. Setelah terisi penuh dan padat, meratakan permukaan campuran.

f. Benda Uji dibiarkan kering hingga 24 jam sebelum dilakukan perawatan.

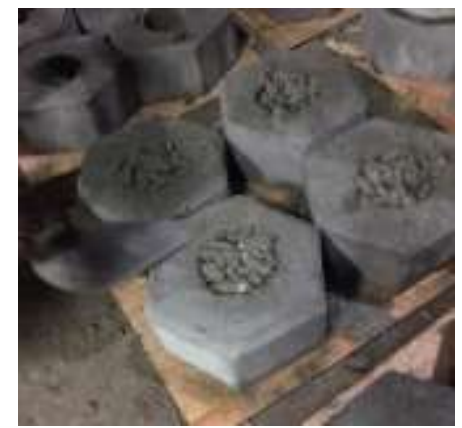

Gambar 5. Beton Porous pada Bagian Tengan Paving Block

\section{Perawatan Benda Uji}

Perawatan benda uji dilakukan dengan menyelimuti benda uji menggunakan karung/goni yang telah dibasahkan setelah benda uji berumur 1 hari. Setiap 3 hari sekali goni/karung dibasahkan kembali agar keadaan benda uji tetap lembab. Goni/karung basah yang sudah dibentang di atas benda uji kemudian ditutupi lagi dengan plastik untuk memperlambat terjadinya penguapan. Perawatan benda uji ini dilakukan selama 28 hari dan dapat dilihat pada Gambar 6.

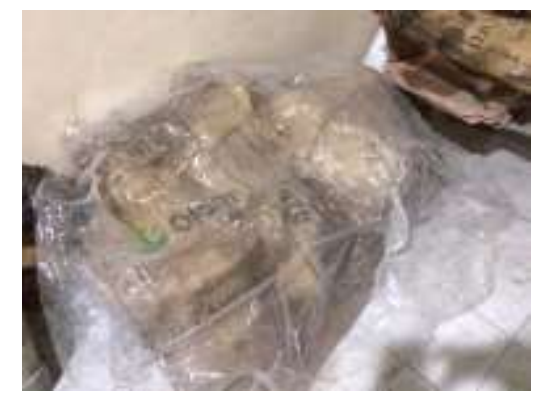

Gambar 6. Perawatan (Curing) Benda Uji

\section{Pemeriksaan Sifat Fisik Benda Uji}

\section{Densitas}

Prosedur pengujian densitas adalah kemudian menimbang berat benda uji dan menghitung volume benda uji.

2. Absorbsi

Prosedur pengujian absorbsi adalah pertama merendam benda uji di dalam air hingga jenuh (selama \pm 24 jam) dan timbang beratnya dalam keadaan basah. Kemudian dikeringkan di dalam oven selama \pm 24 jam pada suhu kurang lebih $105^{\circ} \mathrm{C}$, selanjutnya timbang kembali beratnya dalam keadaan kering.
3. Laju Infiltrasi

Prosedur pengujian laju infiltrasi adalah pertama tempelkan plastik yang cukup tebal pada benda uji menggunakan perekat, dapat dilihat pada Gambar 7. Lalu beri dua tanda di plastik tersebut untuk menandakan mulai menghitung waktu dan untuk memberhentikan waktu. Siapkan stopwacth dan masukkan air hingga air berada diatas tanda mulai menghitung. Lalu mulai menghitung waktu menggunakan stopwacth apabila air sudah sejajar dengan garis pertama, setelah air sejajar dengan garis kedua hentikan waktu pada stopwatch.

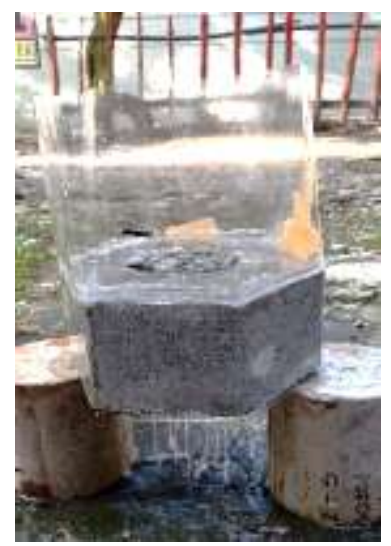

Gambar 7. Pengujian Laju Infiltrasi

\section{HASIL DAN PEMBAHANSAN}

\section{Hasil Pemeriksaan Karakteristik Material Campuran Benda Uji}

Pemeriksaan karakteristik material campuran paving block komposit dilakukan di Laboratorium Teknologi Bahan Program Studi S1 Teknik Sipil Fakultas Teknik Universitas Riau.

1. Hasil Pemeriksaan Karakteristik Agregat Kasar

Dari pengujian karakteristik agregat kasar akan didapat berbagai hal seperti kepadatan agregat, ketahanan agregat hingga penyerapan air. Hasil pengujian karakteristik agregat kasar dapat dilihat pada Tabel 4.

Tabel 4. Hasil Pemeriksaan Karakteristik Agregat Kasar

\begin{tabular}{|c|c|c|c|}
\hline No. & Jenis Pemeriksaan & Hasil & $\begin{array}{c}\text { Standar } \\
\text { Spesifikasi }\end{array}$ \\
\hline 1 & Kadar air (\%) & 2,93 & $3,0-5,0$ \\
\hline \multirow[t]{5}{*}{2} & Berat jenis $\left(\mathrm{g} / \mathrm{cm}^{3}\right)$ & & \\
\hline & $\begin{array}{l}\text { a. Apparent specific } \\
\text { gravity }\end{array}$ & 2,66 & $2,5-2,8$ \\
\hline & $\begin{array}{l}\text { b. Bulk specific } \\
\text { gravity (kering) }\end{array}$ & 2,51 & $2,5-2,8$ \\
\hline & $\begin{array}{l}\text { c. Bulk specific } \\
\text { gravity (ssd) }\end{array}$ & 2,56 & $2,5-2,8$ \\
\hline & d. Absorption (\%) & 2,22 & $2,0-7,0$ \\
\hline 3 & Berat volume $\left(\mathrm{g} / \mathrm{cm}^{3}\right)$ & & \\
\hline
\end{tabular}




\begin{tabular}{llcc} 
& a. Kondisi gembur & 1,36 & $1,4-1,9$ \\
& b. Kondisi padat & 1,48 & $1,4-1,9$ \\
4 & Ketahan aus (\%) & 47,62 & $<40$ \\
5 & Modulus kehalusan & 6,75 & $5,0-8,0$ \\
\hline
\end{tabular}

2. Hasil Pemeriksaan Karakteristik Agregat Kasar

Karakteristik pada agregat halus mempengaruhi kinerja dalam pengikatan antar agregat dan pasta semen. Hasil pengujian karakteristik agregat kasar dapat dilihat pada Tabel 5.

Tabel 5. Hasil Pemeriksaan Karakteristik Agregat Halus

\begin{tabular}{|c|c|c|c|}
\hline No. & Jenis Pemeriksaan & Hasil & $\begin{array}{c}\text { Standar } \\
\text { Spesifikasi }\end{array}$ \\
\hline 1 & Kadar air $(\%)$ & 4,17 & $3,0-5,0$ \\
\hline 2 & Berat jenis $\left(\mathrm{g} / \mathrm{cm}^{3}\right)$ & & \\
\hline & $\begin{array}{l}\text { a. Apparent specific } \\
\text { gravity }\end{array}$ & 2,65 & $2,5-2,8$ \\
\hline & $\begin{array}{l}\text { b. Bulk specific } \\
\text { gravity (kering) }\end{array}$ & 2,59 & $2,5-2,8$ \\
\hline & $\begin{array}{l}\text { c. Bulk specific } \\
\text { gravity (ssd) }\end{array}$ & 2,61 & $2,5-2,8$ \\
\hline & d. Absorption (\%) & 0,91 & $2,0-7,0$ \\
\hline 3 & Berat volume $\left(\mathrm{g} / \mathrm{cm}^{3}\right)$ & & \\
\hline & a. Kondisi gembur & 1,42 & $1,4-1,9$ \\
\hline & b. Kondisi padat & 1,61 & $1,4-1,9$ \\
\hline 4 & Modulus kehalusan & 2,57 & $1,5-3,8$ \\
\hline 5 & Kadar lumpur (\%) & 1,18 & $<5$ \\
\hline 6 & Kandungan organik & \multicolumn{2}{|c|}{ Organic Plate } \\
\hline
\end{tabular}

\section{Hasil Pengujian Densitas}

Hasil pengujian densitas dari setiap variasi paving block komposit dapat dilihat pada Gambar 8 .

Gambar 8. menunjukkan bahwa semakin menurunnya nilai densitas benda uji terhadap persentase volume beton porous pada bagian tengah paving block secara linear. Hal ini dikarenakan oleh pori-pori beton porous pada paving block komposit, sehingga kerapatan antar partikel-partikelnya akan semakin berkurang. Kerapatan ini juga dapat dipengaruhi oleh banyaknya pori-pori pada beton porous, jumlah volume air yang digunakan pada proses pengadukan paving block dan beton porous, serta kekuatan mesin press pada saat mencetak paving block.

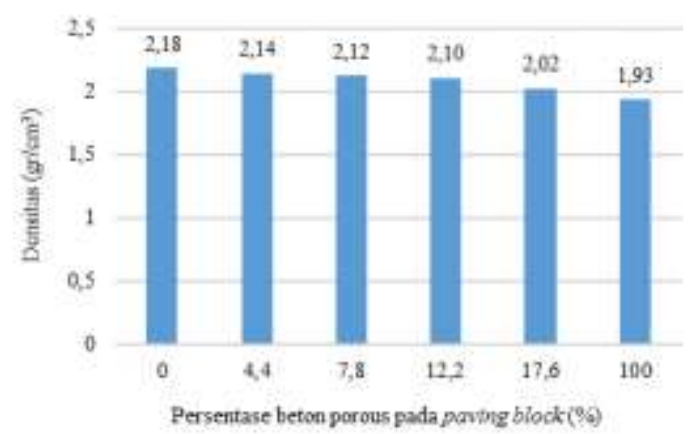

Gambar 8. Hasil Pengujan Densitas

Densitas rata-rata tertinggi dimiliki oleh variasi paving block normal yaitu sebesar $2,18 \mathrm{gr} / \mathrm{cm}^{3}$ sedangkan nilai densitas rata-rata terendah dimiliki oleh variasi paving block porous yaitu sebesar 1,93 $\mathrm{gr} / \mathrm{cm}^{3}$.

Pada inovasi paving block komposit variasi diameter $11 \frac{1}{2}$ ", 2", $21 \frac{1}{2}$ ", dan 3" nilai densitas yaitu sebesar 2,$14 ; 2,12 ; 2,10$ dan $2,02 \mathrm{gr} / \mathrm{cm}^{3}$. Menurut ASTM C 1688-08 beton porous memiliki nilai densitas sekitar 1,75 sampai $2 \mathrm{gr} / \mathrm{cm}^{3}$. Sedangkan paving block memiliki nilai densitas sekitar 1,75 sampai $2 \mathrm{gr} / \mathrm{cm}^{3}$. Sedangkan paving block yang umum dijual dipasaran memiliki nilai densitas rata-rata sekitar 2 $\mathrm{gr} / \mathrm{cm}^{3}$. Jadi, nilai densitas inovasi paving block komposit lebih tinggi dari nilai densitas beton porous maupun nilai densitas paving block.

\section{Hasil Pengujian Absorbsi}

Hasil pengujian absorbsi dari setiap variasi paving block komposit dapat dilihat pada Gambar 9.

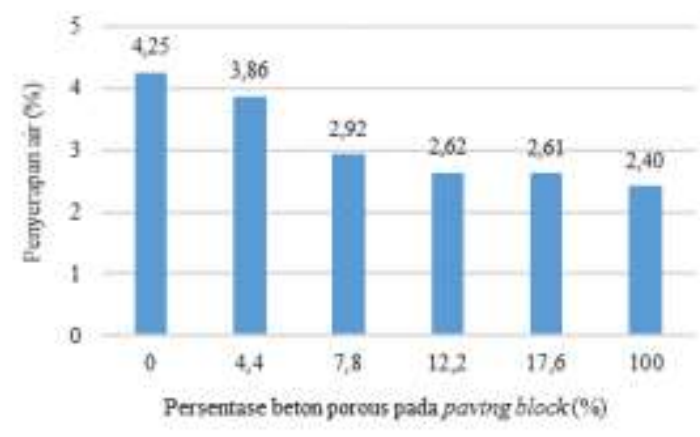

Gambar 9. Hasil Pengujian Absorbsi

Serapan air rata-rata tertinggi dimiliki oleh variasi paving block normal yaitu sebesar 4,25\%. Nilai serapan air rata-rata terendah dimiliki oleh variasi paving block porous yaitu sebesar $2,40 \%$. Pada Gambar 9 dapat disimpulkan nilai rata-rata penyerapan air semakin berkurang seiring dengan bertambahnya pori-pori pada beton porous. Hal ini disebabkan nilai daya serap air pada beton porous 
tidak dapat menjadi acuan karena sifat beton porous dapat meloloskan air bukan menyerap air.

Menurut SNI 03-0691-1996, nilai penyerapan air paving block termasuk ke dalam mutu B yaitu penyerapan air rata-rata maksimal sebesar $6 \%$.

\section{Hasil Pengujian Laju Infiltrasi}

Nilai daya tembus air beton porous lebih besar dibandingkan dengan nilai daya tembus air pada beton normal atau paving block, karena porositas beton porous mampu mengalirkan air lebih cepat sedangkan beton normal atau paving block mengalirkan air lebih lambat. Nilai daya tembus air atau laju infiltrasi rata-rata dari setiap variasi dapat dilihat pada Gambar 10.

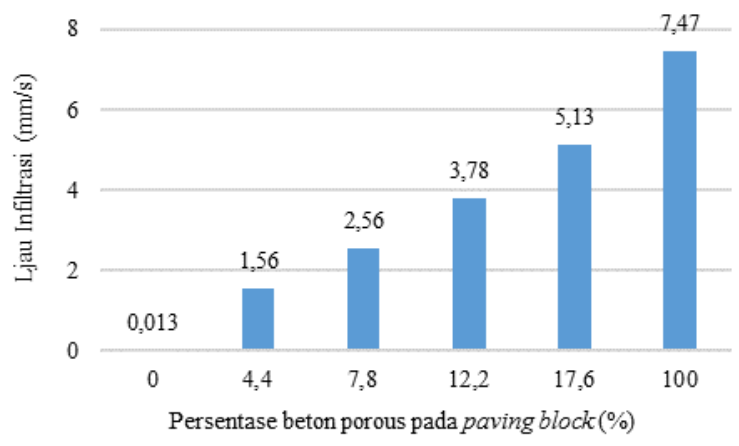

Gambar 10. Hasil Pengujian Laju Infiltrasi

Hasil laju infiltrasi pada Gambar 10 menunjukkan bahwa paving block porous merupakan sampel yang memiliki nilai laju infiltrasi paling besar yaitu $7,47 \mathrm{~mm} / \mathrm{s}$, sedangkan paving block normal merupakan sampel yang memiliki nilai laju infiltrasi paling kecil yaitu $0,013 \mathrm{~mm} / \mathrm{s}$.

Dapat disimpulkan nilai rata-rata laju infiltrasi semakin meningkat seiring dengan bertambahnya pori-pori pada beton porous. Hal ini menyebabkan laju infiltrasi dipengaruhi oleh rongga atau pori pada beton porous sehingga air lolos melewati rongga antar agregat tersebut bukan melalu pori agregat.

\section{Hubungan Kuat Tekan dan Laju Infiltrasi}

Nilai kuat tekan dan nilai laju infiltrasi dapat dilihat pada Tabel 6 .

Tabel 6. Nilai Kuat Tekan dan Laju Infiltrasi

\begin{tabular}{cccc}
\hline \multirow{2}{*}{ Variasi } & Kuat Tekan & Laju Infilrasi & \multirow{2}{*}{ Keterangan } \\
\cline { 2 - 3 } & $\mathrm{MPa}$ & $\mathrm{mm} / \mathrm{s}$ & \\
\hline Normal & 48,19 & 0,013 & Jalan \\
$11^{1} \mathbf{2}^{\prime}$ & 36,33 & 1,56 & Jalan \\
$2^{\prime}$ & 22,09 & 2,56 & Lap. parkir \\
$2 \mathbf{1}^{\prime} \mathbf{2}^{\prime}$ & 19,59 & 3,78 & Lap. parkir \\
$3^{\prime}$ & 13,70 & 5,13 & Trotoar \\
Porous & 11,89 & 7,47 & Taman \\
\hline
\end{tabular}

Berdasarkan SNI 03-0691-1996, paving block normal yang dapat digunakan untuk jalan memiliki nilai laju infiltrasi sebesar $0,013 \mathrm{~mm} / \mathrm{s}$. Pada inovasi paving block komposit 1 1/2yang dapat digunakan untuk jalan memiliki nilai kemampuan meloloskan air atau laju infiltrasi sebesar 1,56 mm/s, inovasi paving block komposit 2' yang dapat digunakan sebagai peralatan parkir memiliki nilai laju infiltrasi sebesar 2,56 mm/s, inovasi paving block komposit 2 $1 / 2$ ' yang dapat digunakan sebagai peralatan parkir memiliki laju infiltrasi sebesar $3,78 \mathrm{~mm} / \mathrm{s}$, dan inovasi paving block komposit 3' yang dapat digunakan untuk pejalan kaki memiliki laju infiltrasi sebesar 5,13 mm/s. Sedangkan paving block porous yang hanya dapat digunakan sebatas perkerasan taman, memiliki nilai laju infiltrasi sebesar 7,47 $\mathrm{mm} / \mathrm{s}$.

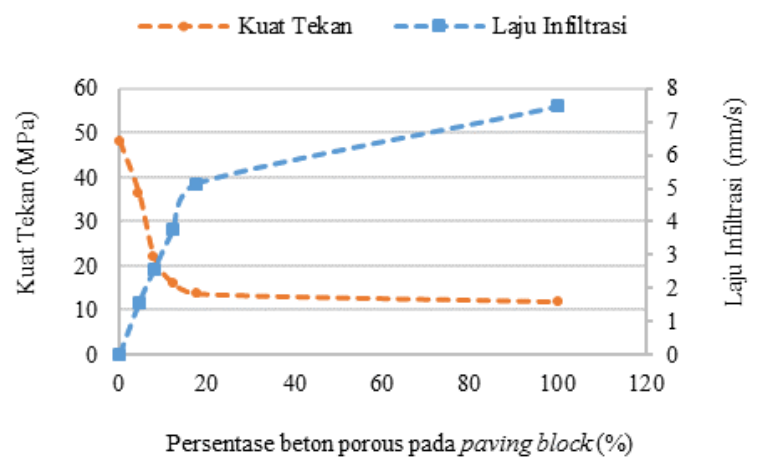

Gambar 11. Hubungan Kuat Tekan dan Laju Infiltrasi

Pada Gambar 11 menunjukkan hubungan antara nilai kuat tekan dengan nilai laju infiltrasi setiap variasi paving block komposit. Penggabungan dua nilai tersebut didapat titik pertemuan antara dua garis trendline, yaitu titik nilai optimum kuat tekan dan laju infiltrasi. Didapat nilai optimum kuat tekan yaitu sebesar 20,8 MPa sedangkan nilai optimum laju infiltrasi sebesar $2,78 \mathrm{~mm} / \mathrm{s}$.

\section{KESIMPULAN DAN SARAN}

\section{Kesimpulan}

Kesimpulan yang didapat dari penelitian ini yaitu :

1. Berdasarkan SNI 03-0691-1996, paving block normal dan paving block komposit $1 \frac{1 / 2}{2}$ dapat digunakan untuk perkerasan jalan, paving block komposit 2' dan $2 \frac{1 / 2}{2}$ dapat digunakan untuk peralatan parkir, paving block komposit 3' dapat digunakan untuk perkerasan trotoar atau pejalan kaki, dan paving block porous dapat digunakan untuk perkerasan taman.

2. Diperoleh nilai optimum kuat tekan inovasi paving block komposit yaitu sebesar 20,8 $\mathrm{MPa}$ dengan nilai optimum laju infiltrasi sebesar 2,78 $\mathrm{mm} / \mathrm{s}$. Dapat disimpulkan, inovasi paving block 
komposit dapat dijadikan sebagai alternatif lapis perkerasan dan memiliki kemampuan meloloskan air atau bersifat permeable sehingga memungkinkan untuk mengurangi genangangenangan air.

\section{Saran}

1. Perlu dilakukan penelitian selanjutnya mengenai persentase penggunaan silika fume, fiber dan abu batu agar mendapatkan hasil yang lbih maksimal.

2. Penelitian ini menggunakan nilai FAS 0,4 dan perbandingan 1 (semen) : 3 (agregat) untuk campuran beton porous, diharapkan untuk penelitian selanjutnya lebih memvariasikan nilai FAS dan perbandingan semen : agregat untuk mendapatkan hasil yang lebih maksimal.

3. Perlu dilakukan penelitian dengan menggunakan diameter agregat kasar yang lebih kecil untuk campuran beton porous.

4. Perlu dilakukan penelitian lebih lanjut mengenai pengaplikasian paving block komposit dilapangan.

\section{DAFTAR PUSTAKA}

[1] ACI 522R. 2010. Report on Pervious Concrete. American Concrete Institute.

[2] ASTM C 1688M. 2010. "Standard Test Method for Density and Void Content of Freshly Mixed Pervious Concrete."

[3] ASTM C 618-86. 2003. "Standard Specification for Coal Fly Ash and Raw or Calcined Natural Pozzolan for use in Concrete."

[4] ASTM C1701. 2017. "Standard Test Method forInfiltration Rate of In Place Pervious Concrete."

[5] Ginting, Arusmalem. 2015. "Kuat Tekan dan Porositas Beton Porous dengan Bahan Pengisi Styrofoam." Jurnal Teknik Sipil Volume 11 Nomor 2.

[6] Kusuma, Dwi. 2012. "Beton Non Pasir (No Fines Concrete)."

[7] SNI 03-0691. 1996. Bata Beton (Paving Block). Jakarta: Badan Standarisasi Nasional. 